\title{
From Adoption to Action: Mapping Technology Adoption Constructs For the Small to Medium Enterprise Innovation Success
}

\author{
Daniel Norris, University Of South Carolina, DNORRIS@SC.EDU \\ Roger Yin, University Of Wisconsin-Whitewater, vinl@uww.edu
}

\begin{abstract}
This paper proposes an action learning centered interpretation of technology adoption variables as they relate to small and medium enterprises (SMEs). Action learning has a long history of successful leadership and executive development as part of a change management effort. Change in organizations today often involves technology innovation adoption. For the SME, technological change is uniquely impactful due to limitations in expertise, short process cycles, and limited resources in general. Information and communication technologies (ICT) can provide a competitive advantage for SMEs if the adoption process is effectively managed. Action learning focuses on aligning the individual with organizational goals in a way that creates a culture of ongoing learning, reflection, and realignment if necessary. Tthe hypothesis of this proposal is that the psychometric constructs used to predict adoption success can be mapped to four actionable change management categories, thus providing a plan for a successful change. Since this hypothesis does not lend itself at this stage to precise analytical techniques a Delphi technique is proposed using a sample of 25 senior managers from information intensive SMEs. The results will be analyzed to provide a philosophical foundation. The technology adoption constructs chosen for this research are from the eight most widely cited technology adoption theories. The effectiveness of these theories to explain adoption of technology is widely established in prior research.
\end{abstract}

Keywords: technology adoption, action learning, change management, small and medium enterprises, SME adoption barriers, training, rollout management, IT project management, innovation implementation

\section{INTRODUCTION}

Porter (Porter, 1991) contends that markets shape the structure of business and today, information and communication technology (ICT) is part of how business responds to market forces. In this bustling knowledge economy, businesses react to information. Small to medium enterprises (SME) are a microcosm of this action-reaction helix of organizational growth or demise. This paper defines small to medium enterprises (SME) as any business from 1 to 250 employees (McAdam \& Reid, 2005). These enterprises include everything from small or homebased offices to small manufacturing operations. For that reason, SMEs are a good choice when trying to understand organizational change (Senge, 1990). Another reason for studying SMEs is that they occupy a valuable niche globally. For example, according to the U.S. Department of Commerce export database (U.S. Department of Commerce, 2003), a total of 218,382 SMEs exported goods from the United States in 2003, which accounted for $97 \%$ of all U.S. exporters. In the Netherlands, SMEs employed $60 \%$ of the workforce in 2004 (Boekhoudt \& Petra van der Stappen, 2004). Furthermore, the World Bank recognizes that SMEs potentially offer greater efficiency, more productivity, and by increasing employment can offer struggling economies a chance to rise from poverty (Beck, Demirguc-Kunt, \& Levine, 2005).

The quick "access to world markets, low-cost entry into new markets and the ability to gain efficiencies in business processes" (Wickramansinghe \& Sharma, 2005, p. 141) is crucial to SME success. This is where ICT enters the picture with its potential for a cost-effective process, innovative services, and a possibly (however short) competitive edge if deployed and used intelligently.

With so much at stake, why then do trade magazines and academic literature both suggest that SMEs in particular are characterized by low or ineffective technology adoption (Bach, 2002; Friedman, 2004; Trembly, 2004)? The reason is that it is simply not enough to own technology; it has to be put to work. Getting technology from adoption to full and effective implementation is a path on which many SMEs stumble. Analysts suggest that small and medium businesses are under researched with regard to how technology is adopted (Riemenschneider, Harrison, \& Mykytyn, 2003) and effectively implemented (Cragg \& Zinatelli, 1995). In fact, there is no research that we could find that explores this relationship beyond innovation diffusion (see (See Rogers, 1983). This study proposes to address this 
research gap by constructing specific organizational actions and/or behaviors that promote effective ICT implementations.

\section{Unique Conditions of SME Technology Adoption}

Dholakia and Kshetri (2004) summarize the uniqueness SME adoption literature when they point to the uniqueness of SMEs as a function of how they relate to internal and external factors of individual environments. For example SMEs are usually flatter organizations with more centralized decision processes and with a high sensitivity to price fluctuations whether in raw material or the target market (Gagnon, Sicotte, \& Posada, 2000). Literature on SME technology adoption is consistent on several factors that impede adoption. The most commonly cited are cost (Wymer \& Regan, 2005) of the technology and lack of applicable in-house knowledge or experience (Smallbone, North, Roper, \& Vickers, 2003). Since SMEs often operate on small margins (Gagnon et al., 2000) any technology that does not translate directly and quickly into a competitive advantage would be seen as a risky investment.

Due to this susceptibility to internal and external forces, SMEs tend to take a short-range view when adopting technologies (Thong, Chee-Sing, \& Raman, 1996). The individual SME is under severe competitive forces. The 2000 United States Census data indicates that $34 \%$ of small business startups fail within the first two years and $56 \%$ of the remaining businesses fail in the subsequent two years (Knaup, 2005). Analysts cite one consistent reason for these failures; poor or inflexible planning (Chunchi \& Young, 2003; Michael \& Combs, 2008; Perry, 2001; Pušnik \& Tajnikar, 2008). This proposed study focuses on this weakness as we develop the framework.

\section{The Framework of the Study}

Technology innovation is organizational change. Organizational change is managed through learning and when accomplished effectively, results in an organization that is better prepared for future change (Senge, 1990). Senge's work on learning organizations promotes individual learning as a fundamental component to organizational change. The organization must have a clear direction and create a learning culture that supports the achievement of the goals of the change. The culture is created with managerial commitment and effective training management. Once the executives are behind the goals of the change, trainers can plan out the design of the learning culture which incorporates an understanding of organizational resources, employee experience levels, and the context or environment in which that change must happen. Technology adoption variables are behaviors that can be manipulated at the organizational and individual levels which conceptually will facilitate the development of a learning framework. The theoretical foundation on which we propose to manipulate the adoption behavior variables is the widely studied technique of action learning.

According to, Marquardt (1999) “Action learning's greatest value is its capacity for equipping individuals, teams and organizations to more effectively respond to change" (p. 4). There are at least four prerequisites for action learning methods to be applied (Marquardt, 1999).

1. There must be an organizational problem, task, or issue that needs to be addressed in a given time frame.

2. The project must be feasible given organizational resources.

3. The project must fit within the range of experience of the group or organization.

4. The problem must be a problem and not a puzzle. Puzzles are solved when the pre-existing answer is discovered. Problems take innovation to solve.

Technology adoption issues fulfill these prerequisites. The real value in the action learning process is that it is capable of working both on and around the change processes. An ICT project does not exist in a vacuum. Any change in technology affects the organization as a whole and has both intended and unintended effects (447 book). Action learning focuses on 6 key areas (Marquardt, 1999).

1. The problem

2. The group (both targeted and periphery)

3. The resolution to take action

4. Question and Reflection

5. Commitment to learning

6. A facilitator

Here, we define the problem as any ICT project. We view the problem as the context in which the adoption variables are manipulated. We define the group as the change stake holders or all those that can effect and affect the change. We define commitment as the level to which upper management and executives are engaged in achieving the target outcomes of the ICT project. We will determine this commitment by the adoption variables that develop a 
supportive environment and a positive learning culture. Questioning and reflection compose the key group that will henceforth be referred to as, training. Marquardt (1999) points out that question and reflection form a process in which the problem or, in this case, the project is clarified and the solution or target is defined. We see commitment to learning and a facilitator as part of the training process overall and therefore combine areas four five and six into the training area for this study.

For this study there are four action learning groups or areas of focused adoption enhancement. These four areas are based on the six key elements and are defined in the next section along with a short summation of almost 20 years of adoption research.

\section{From Adoption to Action}

Technology adoption research is just shy of two decades old. The research encompasses sampling of firms of varying sizes and has forged eight dominant theories of adoption incorporating 22 psycho-social behavioral variables (see Appendix A). The primary body of research evolved primarily from the work of Ajzen and Fishbein's on their theory of reasoned action (TRA). One of the first models was the technology acceptance model (TAM) developed by Fred Davis and Richard Bagozzi (Bagozzi, Davis, \& Warshaw, 1992; Davis, Bagozzi, \& Warshaw, 1989). TAM augments TRA's attitude measures by adding user perceptions of ease of use, and usefulness. The elements of TRA and TAM as one might expect are behavioral. In essence they say that when someone forms an intention to perform a behavior, that they will be able to perform it without limitation (Davis, 1986)which is one of the main criticisms of TAM (Lee, Kozar, \& Larson, 2003). In most organizations there are constraints on certain acts while others are facilitated (Sun \& Zhang, 2005). Free and unimpeded action is not part of the real world.

TAM is very individual focused while other models of adoption focus on how the innovation diffuses throughout an organization. The father of innovation diffusion theory is Everett Rogers (1983) who studied how, why, and at what rate new ideas and technology spread through organizations or cultures. Rogers' work did not concentrate on technology but on any innovation regardless of genre. From his base however the concepts of early or late stage adoption, social influence, voluntariness of use, facilitating conditions, and relative advantage have become foundational components in a number of theories.

Of the eight theories that emerged from the foundation of TAM and innovation diffusion, the only theory that deviates completely is the social cognitive theory based on Bandura's (1977) social learning theory. Social cognitive theory focuses on how the individual sees their own capabilities in relation to the capabilities and social perceptions of those around them rather than how the individual perceives the technology itself (Compeau \& Higgins, 1995).

From the three perspectives of individual perceptions, environmental pathways, and the social self, twenty three core constructs have be divined to explain technology uptake into an organization. The twentytwo core constructs from the adoption literature overview are explained in appendix A. At some level, all have contributed to explaining adoption of ICT but when viewed as a list, they offer little to the IT manager regarding actions toward effective implementations. When viewed with an eye toward an action learning plan the variables suggest both internal (learner or group centered) and external (outside the learner in the environment) influences. The action learning areas of commitment and training house the variables that are external to the learner. The areas of end-users/groups and experience are internal to the learner as an individual or as an learning organization which is perceived as an individual in the sense that it is capable of learning (Senge, 1990). The following figure lists the 22 psycho-social constructs and maps them to the four action learning areas. The mappings are based on how each construct is defined in literature. Overlapping is expected to exist but will be one of the areas of investigation of this study. The following figures are the definitions of each action learning area and a discussion of how they relate to the constructs to which they are mapped. Each connecting line represents the hypothesized mapping relationship. 


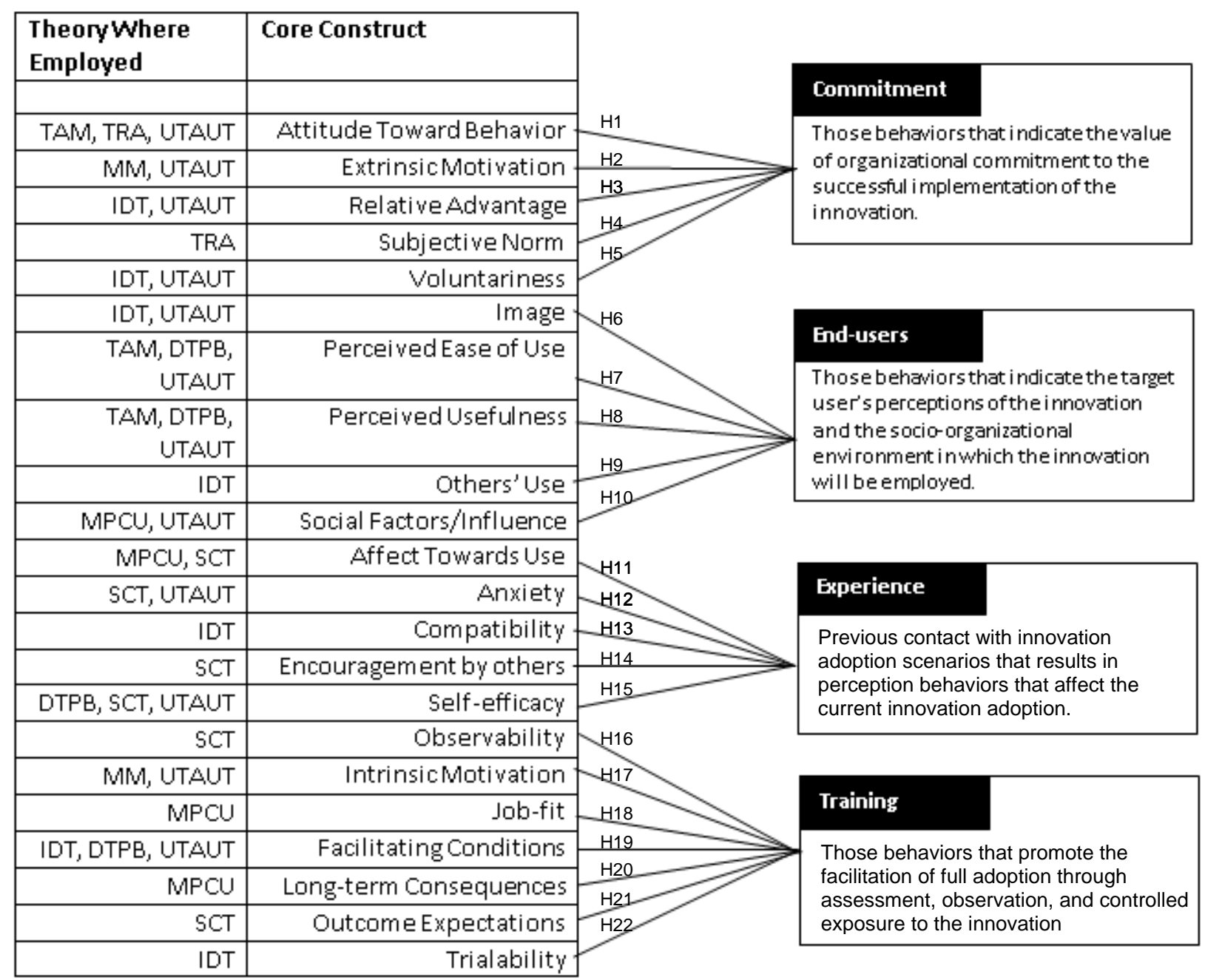

Figure 1: The hypothesized mappings of adoption variables to key action learning areas.

Commitment of Management-defined for this study as those behaviors that indicate the value of organizational commitment to the successful implementation of the innovation. The attitude of the owner/manager of the SME shapes not only the social and business climate, (Drucker, 1994) but also shapes the organizational attitude toward technological innovations (Harrison, Mykytyn Jr, \& Riemenschneider, 1997). Ajzen (Ajzen \& Fishbein, 1972) defined the construct of subjective norm as “The person's perception that most people who are important to him think he should or should not perform the behavior in question” (p. 306). Management holds key sway over the culture of the organization and expectation of personnel (Senge, 1990) . In addition, Wang et al. (Wang, Teo, Wie, Sia, \& Lee, 2002) found support for management's effect on successful technology adoption. Specifically, they found support for their hypothesis that "if a manager's attitude toward the information technology is positive and favorable, ... he/she would dictate his/her firm to act more aggressively in technology adoption” (p. 3). Findings such as this indicate that the theory of reasoned action is consistent with the suggestion that a successful rollout begins with managerial commitment to the technology.

Management also has an enforcement control option termed here as "voluntariness" which is a continuous variable that can range from strictly voluntary to strictly involuntary. Research has found that in small business often a more entrepreneurial attitude toward the implementation of the technology gives an impression of sharing of ideas and therefore promotes higher quality results (Green, Collins, \& Hevner, 2004). Too much of an aloof attitude by management might also be interpreted as uncertainty which, depending on the number of employees, might 
undermine the development of extrinsic motivations (Hwang, 2005).

End-users/groups- defined for this study as those behaviors that indicate the target user's perceptions of the innovation and the social and organizational environment in which the innovation will be employed. Information communication technology is highly configurable offering a high degree of customization potential at both the organizational and individual levels. The application of the technology acceptance model (TAM) provides a number of insights into ICT deployment from the individual adoption perspective. Wymer and Regan (2005), for instance, point out that perceptions of usefulness and of ease of use vary between adopters and nonadopters. This suggests that it is important to identify how the end-user will productively apply the information technologies. End-user perceptions could be measured before the implementation which would serve to gather information on what expected support systems, preferred training methods, and perceptions of the importance of the innovation to their productivity. A pre-implementation survey would also introduce the innovation to end-users in an unassuming way avoiding possible misconceptions of managerial uncertainty.

The image variable is also an important, for it suggests that end-users want to be perceived as participative and loyal. The concept is that the more visible the outcome of the innovation, the more likely it is that people will adopt it. Here too, firm size is a factor in how much of an impact image will have on the success of an innovation deployment (Hannan \& McDowell, 1987; Parente \& Prescott, 1994; Stoneman \& Kwon, 1996)

Experience- defined for this study as previous contact with innovation adoption scenarios that results in perception behaviors that affect the current innovation adoption. Research consistently finds prior experience plays a key role in technology adoption. Effective adoption of ICT is a function of management's experience with the target technology (Venkatesh \& Speier, 1999). Beliefs, attitudes and experience level of management can impede or facilitate implementation of targeted technologies (Gagnon et al., 2000; Harrison et al., 1997; Thong et al., 1996). As experience increases enjoyment or affect toward use of the system also increases (Conrad, 2002). Managers must inventory their own experience and knowledge regarding their technology goals, as well as that of their staff and consider them resources in the implementation. This inventory creates a foundation of experience from which to draw, allowing the various knowledge sources to create a support network (Boekhoudt \& Petra van der Stappen, 2004). This networking may take considerable up-front work and time, but it can have big dividends in the long run by creating supportive facilitating conditions for quick adoption and future innovation (Boekhoudt \& Petra van der Stappen, 2004).

Training-defined for this study as those behaviors that promote the facilitation of full adoption through assessment, observation, and controlled exposure to the innovation. If the experience and/or knowledge base is thin or non-existent, a base can be created by piloting the implementation with controlled deployment scenarios (Passerini \& Patten, 2005). Research indicates that scenario-based training is effective in IT diffusion efforts (Knol, 2001). It can also help to align technology use with current business goals as unforeseen contexts come to light. Furthermore, pilot testing adds trialability for discovery of the relative advantage of the innovation to both sides of the administrative and end-user equation.

Training efforts, like the implementation itself, takes planning. In a small business training resources are limited. Training takes money, human capital and time away from productivity. The innovation must be ready to implement nearly out of the box. This immediacy is why the variables of long term consequences, outcome expectations, and job-fit are part of the training This study is focused on defining an action plan for a successful implementation of an ICT innovation in a small to medium sized business. To this end we will map the psycho-social constructs of eight adoption theories to four action learning areas using the Delphi methodology.

The Delphi method lends itself well to organizational studies where specific measurement is not a concern. In this study we interview 25 owner or executive management personnel of 25 SMEs across eight industries. As anonymity is an important component of the Delphi method the identities of all interviewees and their associated organizations will be kept confidential.

The element that all organizations in this study share is that they apply ICT systems to conduct business and manage employees. By ICT systems we mean that all employees require a computer to do their job and that mobile technology such as cell phones and PDAs are used as a means of connecting to data and customers. The interviewee has experienced an adoption of a new ICT within the past 12 months. 
The frequency of such use of mobile will be recorded but is not a prerequisite to being interviewed.

The interview method applied is the paradigmatictype narrative in which interviewees are allowed to discuss events as they see fit (Polkinghorne, (Life History and Narrative, By J. Amos Hatch, Richard Wisniewski). The interviews are then analyzed to produce a taxonomy out of the common elements among all interviews. The subject of the interview is their recollection of their latest ICT adoption event, its processes, and an evaluation of the results.

After the interview, study participants will be given a list of all twenty-two constructs. The definition of the each of the action learning areas will be given to them both verbally and in a textual form that they can refer to throughout the exercise. The exercise is to associate the construct as they define them, into one or more of the action learning areas. There is also one additional designation for those constructs that they feel do not fit in any action learning area. The designation of each construct will be will be compiled across all respondents to develop the mapping. Any constructs that are consistently discarded as not fitting into any category will be reanalyzed as to how it is presented in the extent literature. A formal definition will be written and will be discussed in follow-up interviews with respondents. Follow up interviews will be conducted only if the hypotheses of this study are not met or a new concept of the relationships is formed.

process. These three variables align the features of the innovation with both the goals of the organization and the personal productivity needs of the individual.

\section{Methodology \\ Summary}

Small to medium enterprises (SME) comprise an important economic foundation around the globe. Because of issues such as limited resources SMEs are likely to respond to market changes using implementations of technologies. However there is a significant failure rate of information and communication technologies (ICT) which can adversely affect the viable futures of these smaller firms. Adoption research has proven to be useful in explaining the initial acceptance of information and communication technology innovations at both the individual and the organizational level. As important as this explanation is, the behavioral constructs used in the research have offered little regarding the development of effective technology adoption management. The development of an implementation methodology would facilitate a successful ICT adoption by instilling and possibly enhancing the behavioral constructs shown to effect ICT adoption favorably. This study proposes to map specific constructs to one of four key action learning areas. By using the action learning model of organizational develop we will facilitate short and long term cultural change to ensure a current adoption success and better prepare the organization to handle future ICT changes.

\section{BIBLIOGRAPHY}

Ajzen, I., \& Fishbein, M. (1972). Attitudes and normative beliefs as factors influencing behavioral intentions. Journal of Personality and Social Psychology, 21(1), 1-9.

Bach, D. (2002). Slow wireless adoption hits bellwether vendor. American Banker, 167(8), 1.

Bagozzi, R.P., Davis, F.D., \& Warshaw, P.R. (1992). Development and test of a theory of technological learning and usage, Human Relations (Vol. 45, pp. 659): Sage Publications, Ltd.

Bandura, A. (1977). Social learning theory. Englewood Cliffs, N.J.: Prentice Hall.

Beck, T., Demirguc-Kunt, A., \& Levine, R. (2005). SMEs, growth, and poverty: Cross-country evidence. Journal of Economic Growth, 10(3), 199.

Boekhoudt, P., \& Petra van der Stappen. (2004). The aspect project case: A model for SME adoption of ICT innovation. Paper presented at the Sixth International Conference on Electronic Commerce.

Chunchi, W., \& Young, A. (2003). Factors resulting in successes and failures of small businesses in the small business institute program at Syracuse University. Economic Development Quarterly, 17(2), 205.

Compeau, D.R., \& Higgins, C.A. (1995). Application of social cognitive theory to training for computer skills. Information Systems Research, 6(2), 118.

Conrad, D.L. (2002). Engagement, excitement, anxiety, and fear: Learners' experiences of starting an online course. American Journal of Distance Education, 16(4), 205.

Cragg, P.B., \& Zinatelli, N. (1995). The evolution of information systems in small firms. Information \& Management, 29(1), 1-8.

Davis, F.D., Bagozzi, R.P., \& Warshaw, P.R. (1989). User acceptance of computer technology: A comparison of two theoretical models. Management Science, 35(8), 982.

Davis, F.D.J. (1986). A technology acceptance model for testing new end-user information systems: 
Theory and results. Unpublished Ph.D., Massachusetts Institute of Technology, United States -- Massachusetts.

Dholakia, R.R., \& Kshetri, N. (2004). Factors impacting the adoption of the internet among SMEs. Small Business Economics, 23(4), 311322.

Drucker, P.F. (1994). The age of social transformation., Atlantic Monthly (Vol. 274, pp. 53): Atlantic Monthly Group Inc.

Friedman, S. (2004). What's with wireless? National Underwriter / Property \& Casualty Risk \& Benefits Management, 108(24), 5.

Gagnon, Y.-C., Sicotte, H., \& Posada, E. (2000). Impact of SME manager's behavior on the adoption of technology. 25(2), 43.

Green, G.C., Collins, R.W., \& Hevner, A.R. (2004). Perceived control and the diffusion of software process innovations. The Journal of High Technology Management Research, 15(1), 123144.

Hannan, T.H., \& McDowell, J.M. (1987). Rival precedence and the dynamics of technology adoption: An empirical analysis. Economica, 54(214), 155-171.

Harrison, D.A., Mykytyn Jr, P.P., \& Riemenschneider, C.K. (1997). Executive decisions about adoption of information technology in small business: Theory and empirical tests. Information Systems Research, 8(2), 171.

Hwang, Y. (2005). Investigating enterprise systems adoption: Uncertainty avoidance, intrinsic motivation, and the technology acceptance model. European Journal of Information Systems, 14, 150-161.

Knaup, A.E. (2005). Survival and longevity in the business employment dynamics data. Monthly Labor Review, 128(5), 50.

Knol, W.H.C. (2001). The diffusion and adoption of information technology in small-and mediumsized enterprises through it scenarios. Technology Analysis \& Strategic Management, 13(2), 227-246.

Lee, Y., Kozar, K.A., \& Larson, K.R.T. (2003). Technoloy acceptance model: Past, present and future. Communications of the AIS, 12(50), 752780.

Marquardt, M.J. (1999). Action learning in action : Transforming problems and people for worldclass organizational learning (1st ed.). Palo Alto, Calif.: Davies-Black Pub.

McAdam, R., \& Reid, R. (2005). SME and large organization perceptions of knowledge management. Journal of Knowledge Management, 5(3), 231-241.
Michael, S.C., \& Combs, J.G. (2008). Entrepreneurial failure: The case of franchisees. Journal of Small Business Management, 46(1), 73-90.

Parente, S.L., \& Prescott, E.C. (1994). Barriers to technology adoption and development. The Journal of Political Economy, 102(2), 298-321.

Passerini, K., \& Patten, K. (2005). Preparing it organizations for the mobile revolution. Cutter IT Journal, 18, 8.

Perry, S.C. (2001). The relationship between written business plans and the failure of small businesses in the u.S. Journal of Small Business Management, 39(3), 201-208.

Porter, M.E. (1991). Towards a dynamic theory of strategy. Strategic Management Journal, 12, 95117.

Pušnik, K., \& Tajnikar, M. (2008). Technical and cost efficiencies as determinants of business failures of small firms. Eastern European Economics, 46(1), 43-62.

Riemenschneider, C.K., Harrison, D.A., \& Mykytyn, J.P.P. (2003). Understanding it adoption decisions in small business: Integrating current theories. Information \& Management, 40(4), 269.

Rogers, E.M. (1983). Diffusion of innovations (3rd ed.). New York, N.Y.: Free Press ; Collier Macmillan.

Senge, P.M. (1990). The fifth discipline : The art and practice of the learning organization. New York: Doubleday/Currency.

Smallbone, D., North, D., Roper, S., \& Vickers, I. (2003). Innovation and the use of technology in manufacturing plants and SMEs: An interregional comparison. Environment \& Planning C: Government \& Policy, 21(1), 37.

Stoneman, P., \& Kwon, M.J. (1996). Technology adoption and firm profitability. The Economic Journal, 106(437), 952-962.

Sun, H., \& Zhang, P. (2005). The role of moderating factors in user technology acceptance. International Journal of Human-Computer Studies, Forth coming.

Thong, J.Y.L., Chee-Sing, Y., \& Raman, K.S. (1996). Top management support, external expertise and information systems implementation in small businesses. Information Systems Research, 7(2), 248. 
Trembly, A.C. (2004). Wireless adoption outlook 'bleak' for insurance. National Underwriter / Property \& Casualty Risk \& Benefits Management, 108(22), 25.

U.S. Department of Commerce. (2003). Small \& medium-sized exporting companies (Publication. Retrieved 7/7/06: http://www.ita.doc.gov/td/industry/otea/sme_han dbook/SME_index.htm

Venkatesh, V., \& Speier, C. (1999). Computer technology training in the workplace: A longitudinal investigation of the effect of mood. Organizational Behavior \& Human Decision Processes, 79(1), 1.

Wang, X., Teo, H.-H., Wie, K.-K., Sia, C.-L., \& Lee, M. (2002). Effects of learning capacity and knowledge base on executive decision formation for it adoption: An empirical study of small and medium-sized organizations. Unpublished Empirical study. National University of Singapore.

Wickramansinghe, N., \& Sharma, S.K. (2005). Key factors that hinder SMEs in succeeding in today's knowledge-based economy. International Journal of Management and Enterprise Development, 2(2), 141-158.

Wymer, S., \& Regan, E. (2005). Factors influencing e-commerce adoption and use by small and medium businesses. Electronic Markets, 15(4), 438. 


\section{APPENDIX A}

\section{Table 1: Summary of Core Constructs of Adoption}

Core Constructs/Definitions Impact

\section{Technology Acceptance Model and Theory of Reasoned Action}

Attitude toward Behavior: "an individual's positive or negative feelings (evaluative affect) about performing the target behavior" (Fishbein and Ajzen 1975, p. 216).

Subjective Norm: "the person's perception that most people who are important to him think he should or should not perform the behavior in question" (Fishbein and Ajzen 1975, p. 302).

Perceived Ease of Use :"the degree to which a person believes that using a particular system would be free of effort" (Davis 1989, p. 320).

Perceived Usefulness: "the degree to which a person believes that using a particular system would enhance his or her job performance" (Davis 1989, p. 320).

\section{Motivation Model}

Extrinsic Motivation: The perception that users will want to perform an activity "because it is perceived to be instrumental in achieving valued outcomes that are distinct from the activity itself, such as improved job performance, pay, or promotions" (Davis Bagozzi, Warshaw. 1992, p. 1112).

Intrinsic Motivation: The perception that users will want to perform an activity "for no apparent reinforcement other than the process of performing the activity per se" (Davis et al. 1992, p. 1112)
Perceived usefulness strongly influenced peoples' intentions, explaining more than half of the variance in intentions at the end of 14 weeks. Perceived ease of use had a small but significant effect on intentions as well, although this effect subsided over time. Attitudes only partially mediated the effects of these beliefs on intentions. Subjective norms had no effect on intentions. (Davis, Bagozzi, and Warshaw, 1989, p. 982)
Study 1 found that intentions correlated .63 with system usage and that usefulness and enjoyment influenced usage behavior entirely indirectly through their effects on intentions. In both studies, a positive interaction between usefulness and enjoyment was observed. Together, usefulness and enjoyment explained 62\% (Study 1) and 750h (Study 2) of the variance in usage intentions. Moreover, usefulness and enjoyment were found to mediate fully the effects on usage intentions of perceived output quality and perceived ease of use. As hypothesized, a measure of task importance moderated the effects of ease of use and output quality on usefulness but not on enjoyment. (Davis, et. al., 1992, p. 1111) 


\begin{tabular}{|c|c|}
\hline \multicolumn{2}{|l|}{ Model of PC Utilization (MPCU) } \\
\hline $\begin{array}{l}\text { Job-fit: "the extent to which an individual } \\
\text { believes that using [technology] can enhance } \\
\text { the performance of his or her job" } \\
\text { (Thompson et al. 1991, p. 129). }\end{array}$ & \multirow{6}{*}{$\begin{array}{l}\text { The results show that social norms and three components of } \\
\text { expected consequences (complexity of use, fit between the job } \\
\text { and PC capabilities, and long-term consequences) have a strong } \\
\text { influence on utilization. These findings confirm the importance of } \\
\text { the expected consequences of using PC technology, suggesting } \\
\text { that training programs and organizational policies could be } \\
\text { instituted to enhance or modify these expectations. (Thompson, } \\
\text { Higgins, Howell, 1991, p. 125) }\end{array}$} \\
\hline $\begin{array}{l}\text { Complexity: "the degree to which an } \\
\text { innovation is perceived as relatively difficult } \\
\text { to understand and use" (Thompson et al. } \\
\text { 1991, p. 128). }\end{array}$ & \\
\hline $\begin{array}{l}\text { Long-term Consequences: Outcomes that } \\
\text { have a pay-off in the future" (Thompson et } \\
\text { al. 1991, p. 129). }\end{array}$ & \\
\hline $\begin{array}{l}\text { Affect Towards Use: "feelings of joy, elation, } \\
\text { or pleasure, or depression, disgust, } \\
\text { displeasure, or hate associated by an } \\
\text { individual with a particular act" (Thompson } \\
\text { et al. 1991, p. 127). }\end{array}$ & \\
\hline $\begin{array}{l}\text { Social Factors: "the individual's } \\
\text { internalization of the reference group's } \\
\text { subjective culture, and specific interpersonal } \\
\text { agreements that the individual has made } \\
\text { with others, in specific social situations" } \\
\text { (Thompson et al. 1991, p. 126). }\end{array}$ & \\
\hline $\begin{array}{l}\text { Facilitating Conditions: "provision of support } \\
\text { for users of PCs may be one type of } \\
\text { facilitating condition that can influence } \\
\text { system utilization" (Thompson et al. 1991, p. } \\
\text { 129). }\end{array}$ & \\
\hline
\end{tabular}




\begin{tabular}{|c|c|}
\hline \multicolumn{2}{|l|}{ Innovation Diffusion Theory (IDT) } \\
\hline $\begin{array}{l}\text { Relative Advantage: "the degree to which an } \\
\text { innovation is perceived as being better than its } \\
\text { precursor" (Moore and Benbasat, p. 195) }\end{array}$ & \multirow{7}{*}{$\begin{array}{l}\text { "the final instrument, which was developed based on a model } \\
\text { of general factors that have predicted the adoption of } \\
\text { innovations quite successfully, offers a useful tool for the study } \\
\text { of the initial adoption and diffusion of innovations." (Moore } \\
\text { and Benbasat, p. 212) }\end{array}$} \\
\hline $\begin{array}{l}\text { Compatibility: "the degree to which an } \\
\text { innovation is perceived as being consistent with } \\
\text { the existing values, needs, and past experiences } \\
\text { of potential adopters" (Moore and Benbasat, p. } \\
\text { 195) }\end{array}$ & \\
\hline $\begin{array}{l}\text { Complexity: "the degree to which an innovation } \\
\text { is perceived as being difficult to use" (Moore and } \\
\text { Benbasat, p. 195) }\end{array}$ & \\
\hline $\begin{array}{l}\text { Observability: "the degree to which the results } \\
\text { of an innovation are observable to Others" } \\
\text { (Moore and Benbasat, p. 195) }\end{array}$ & \\
\hline $\begin{array}{l}\text { Trialability: "the degree to which an innovation } \\
\text { may be experimented with before adoption" } \\
\text { (Moore and Benbasat, p. 195) }\end{array}$ & \\
\hline $\begin{array}{l}\text { Image: "the degree to which use of an } \\
\text { innovation is perceived to enhance one's image } \\
\text { or status in one's social system" (Moore and } \\
\text { Benbasat, p. 195) }\end{array}$ & \\
\hline $\begin{array}{l}\text { Voluntariness of use:"the degree to which use of } \\
\text { the innovation is perceived as being voluntary, or } \\
\text { of free will" (Moore and Benbasat, p. 195) }\end{array}$ & \\
\hline
\end{tabular}




\begin{tabular}{|c|c|}
\hline \multicolumn{2}{|l|}{ Theory of Planned Behavior (decomposed) (DTPB) } \\
\hline $\begin{array}{l}\text { Perceived behavioral control (PBC) (this was tested } \\
\text { in addition to the TRA constructs of attitude and } \\
\text { subjective norm) Deconstructed constructs of } \\
\text { - PBC "perceptions of internal and } \\
\text { external constraints on behavior" } \\
\text { (Taylor and Todd 1995, p. 149). } \\
\text { - Self Efficacy } \\
\text { - Resource Facilitating Conditions } \\
\text { - Technology Facilitating Conditions }\end{array}$ & $\begin{array}{l}\text { Decomposing the belief structures in the Theory of Planned } \\
\text { Behavior provided a moderate increase in the explanation } \\
\text { of behavioral intention. Overall, the results indicate that the } \\
\text { decomposed Theory of Planned Behavior provides a fuller } \\
\text { understanding of behavioral intention by focusing on the } \\
\text { factors that are likely to influence systems use through the } \\
\text { application of both design and implementation strategies. } \\
\text { (Taylor and Todd, 1995, p. 144) }\end{array}$ \\
\hline \multicolumn{2}{|l|}{ Social Cognitive Theory (SCT) } \\
\hline $\begin{array}{l}\text { Encouragement by others: "within the individual's } \\
\text { reference group-the people to whom an individual } \\
\text { looks to obtain guidance on behavioral } \\
\text { expectations--call be expected to influence both } \\
\text { self-efficacy and outcome expectations." (Compeau } \\
\text { and Higgins, 1995, p. 195) }\end{array}$ & \multirow{7}{*}{$\begin{array}{l}\text { An individual's self-efficacy and outcome expectations were } \\
\text { found to be positively influenced by the encouragement of } \\
\text { others in their work group, as well as others' use of } \\
\text { computers. Thus, self-efficacy represents an important } \\
\text { individual trait, which moderates organizational influences } \\
\text { (such as encouragement and support) on an individual's } \\
\text { decision to use computers. Understanding self-efficacy, } \\
\text { then, is important to the successful implementation of } \\
\text { systems in organizations. The existence of a reliable and } \\
\text { valid measure of self-efficacy makes assessment possible } \\
\text { and should have implications for organizational support, } \\
\text { training, and implementation. (Compeau and Higgins, 1995, } \\
\text { p. 189) }\end{array}$} \\
\hline $\begin{array}{l}\text { Others' Use: “Learning by observation, or behavior } \\
\text { modeling" (Compeau and Higgins, 1995, p. 195) }\end{array}$ & \\
\hline $\begin{array}{l}\text { Support: "The availability of assistance to } \\
\text { individuals who require it" (Compeau and Higgins, } \\
\text { 1995, p. 195) }\end{array}$ & \\
\hline $\begin{array}{l}\text { Computer Self-efficacy: "the outcomes one expects } \\
\text { derive largely from judgments as to how well one } \\
\text { can execute the requisite behavior" (Bandura, } \\
\text { 1978. p. 241). }\end{array}$ & \\
\hline $\begin{array}{l}\text { Outcome Expectations: "The expected } \\
\text { consequences of a behavior" (Compeau and } \\
\text { Higgins, 1995, p. 195) }\end{array}$ & \\
\hline $\begin{array}{l}\text { Affect: "Individuals' affect (Or liking) for particular } \\
\text { behaviors" (Compeau and Higgins, 1995, p. 196) }\end{array}$ & \\
\hline $\begin{array}{l}\text { Anxiety: "Feelings of anxiety surrounding } \\
\text { computers" (Compeau and Higgins, 1995, } \mathrm{p}\end{array}$ & \\
\hline
\end{tabular}




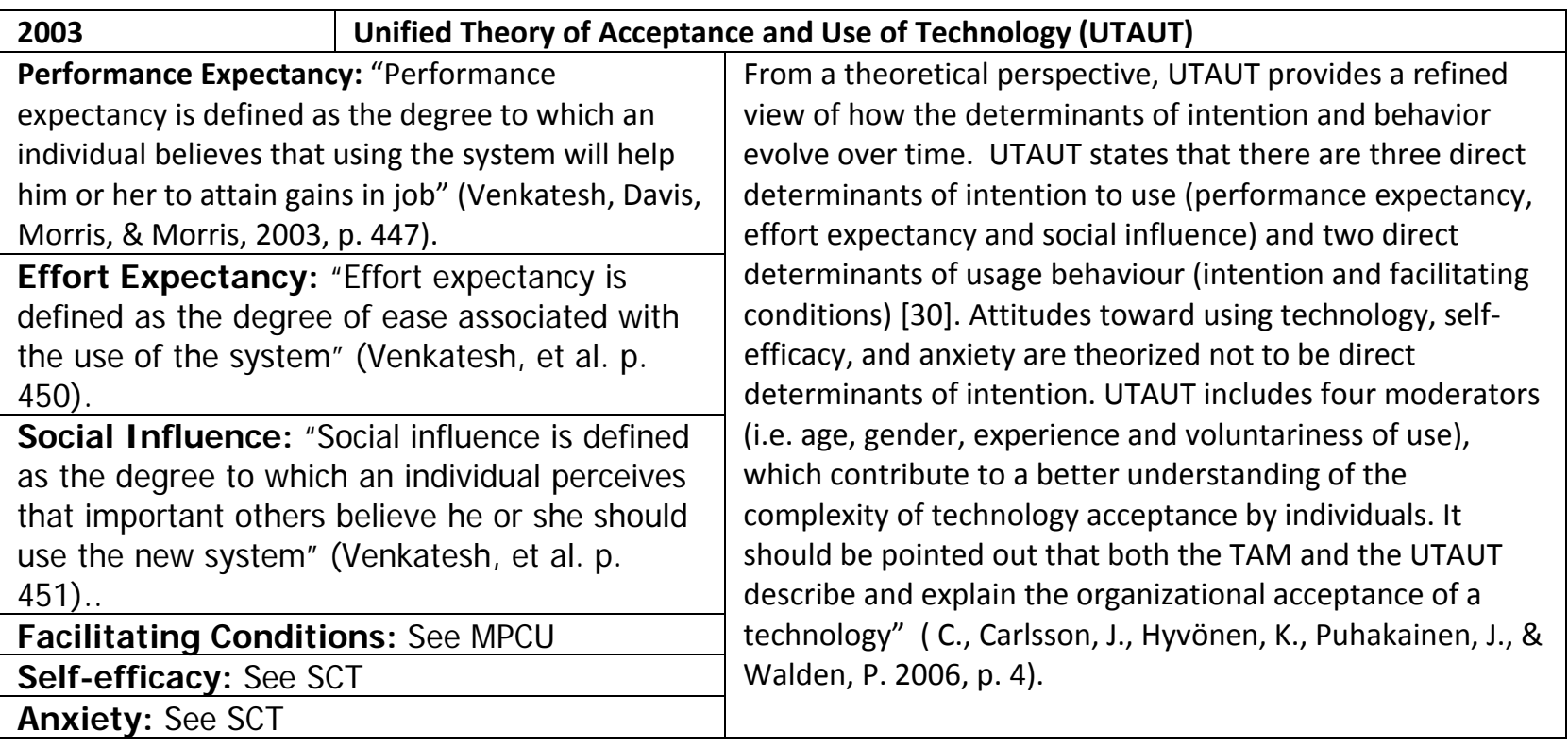

